Euskal ikerketen aldizkaria | Revue d'études basques |

Revista de estudios vascos | Basque studies review

$5 \mid 2000$

Numéro V

\title{
Travaux de Jacques Allières sur le domaine basque
}

\section{Charles Videgain}

\section{OpenEdition}

Journals

Édition électronique

URL : http://journals.openedition.org/lapurdum/1287

DOI : $10.4000 /$ lapurdum. 1287

ISSN : 1965-0655

Éditeur

IKER

Édition imprimée

Date de publication : 1 octobre 2000

Pagination : 9-11

ISBN : 2-84127-161-7

ISSN : $1273-3830$

\section{Référence électronique}

Charles Videgain, «Travaux de Jacques Allières sur le domaine basque », Lapurdum [En ligne], 5 | 2000, mis en ligne le 01 juin 2009, consulté le 02 juillet 2020. URL : http://journals.openedition.org/

lapurdum/1287; DOI : https://doi.org/10.4000/lapurdum.1287 


\section{Travaux de Jacques Allières sur le domaine basque}

Xarles Videgain UMR 5478, UPPA

Nous remercions M. Roché, professeur à l'Université de Toulouse - Le Mirail, de nous avoir fourni la documentation dans laquelle nous sélectionnons les travaux que Jacques Allières a consacrés au domaine basque.

1960-1961: « Petit atlas linguistique basque français Sacaze », I, Via Domitia, VII, 205-211, +15 cartes h.t. : II, Via Domitia, 1961, VIII, 82-126 et I-X +58 cartes h.t.

1963 : «Dialectologie sur les confins basco-romans : l’article défini à Montory (Basses-Pyrénées) 》, Via Domitia, 87-98.

1964 : « Le Recueil Sacaze et les parlers basques français », Actes du $1^{\text {er }}$ Congrès International de Dialectologie Générale de Louvain (1960), 19 p.

1966 : Suggestions pour l'Atlas, Actas del IV. Symposium de Prehistoria Peninsular, «Problemas de la Prehistoria y de la Etnología vascas, Pamplona, 247-255.

1974 : " Langues et parlers », in Les Pyrénées, ouvrage collectif sous la direction de F. Taillefer, Toulouse, 423-458; en outre, "Guide pour la prononciation des noms de lieux pyrénéens », ibid., 493-495.

1977 : Les Basques, collection Que sais-je? n ${ }^{\circ} 1668,128$ p., PUF. $2^{\circ}$ édition 1979 ; traduction espagnole 1978: Los Vascos, coll. EDAF Universitaria; $3^{\mathrm{e} e ́ d i t i o n}$ française $1986 ; 4^{e}$ édition revue et corrigée 1992 ; traduction japonaise Hakusuisha, Tokyo, 1992 ; $5^{\mathrm{e}}$ édition revue et corrigée 1996.

1978 : «Petit Atlas linguistique basque français Bourciez I, (20 cartes commentées) », Fontes Linguae Vasconum 27, 353-386.

1979: « Les versions basque, gasconne et française d'un même dialogue à Labastide-Clairence, point 6910 de l'ALG », in Mémoires dédiés à la mémoire de Jean Séguy, Via Domitia XIV II, 3-19.

1979 : Manuel pratique de basque, Picard, 279 p.

1979 : « Statut et économie des flexions verbales "pluripersonnelles" », Mélanges offerts à André Martinet, La linguistique, 15, 3-30.

1981 : «Dialectologie », Actes des Rencontres internationales de bascologues (Euskalarien nazioarteko jardunaldiak), IKER 1, Bilbao, 273-281. 
1982 : «Les types biscle/biscà et serimana/sirma "poutre faîtière" (ALG III 673) ou les charpentiers basques en Gascogne ", Festscher. F.J. Hubschmid zum 65. Geburst, Berne, 923-935 (2 cartes).

1983 : « De la formalisation du système verbal basque », Piarres Lafitte'ri omenaldia [Hommage à Pierre Lafitte], IKER 2, Bilbao, 37-91.

1984 : Glossaire commenté du vol. du Corpus d'Architecture Rurale Française (dir. J. Cuisenier) consacré aux Pays aquitains : Bordelais, Gascogne, Pays Basques, Béarn, Bigorre, 68-77.

1985 : « Statut et limites du polymorphisme morphologique : le verbe dans la Grammaire cantabrique basque de Pierre d'Urte (1712) (1 $1^{\text {re }}$ partie : verbes intransitifs non auxiliaires) » in Symbolae Ludovico Mitxelena Septuvagenario Oblatae, 908-919.

1986 : « Petit atlas linguistique basque français Bourciez II (30 cartes commentées) ", Fontes Linguae Vasconum, 47, 5-45.

1987 : « Gascón y euskera : afinidades e interrelaciones lingüisticas », in Pirineo navarro-aragonés, Gascón y euskera (ed. R. Ciérvide), Bilbao, 182-198.

1988 : "La géographie linguistique basque d'après l'Euskalerriko Atlas Etnolinguistikoa", in Actes du $2^{e}$ Congrès Mondial Basque (Linguistique : Saint-Sébastien, sept. 1987).

1991 : «Zonas pirenaicas (Proyecto de un atlas lingüistico y etnográfico de ambas vertientes) », Actas del I ${ }^{\text {er }}$ Congreso de lingüistas aragoneses (1988), Zaragoza, 1991, 41-46.

1991 : « Statut et limites du polymorphisme morphologique : le verbe dans la Grammaire Cantabrique basque de Pierre d'Urte (1712) (2 partie : les auxiliaires) », in Memoriae L. Mitxelena Magistri Sacrum, Anuario del Seminario de Filologia vasca « Julio de Urquijo », Gehigarriak, XIV, Saint-Sébastien, 767-812.

1992 : «Vision française du peuple basque », Actes du XI. Congreso de Estudios Vascos, organisé par Eusko-Ikaskuntza, (Saint-Sébastien, 7-11 octobre 1991), 279-284.

1992: «Basque et roman sur leur frontière occidentale d'après les recueils Sacaze et Bourciez (vers 1880) ", Actes du III Congrès de l'Association Internationale d'Études Occitanes (Montpellier 1990), Montpellier, 173-180 + 13 cartes.

1992 : «La place de la variation synchronique ponctuelle dans les monographies dialectales et la géolinguistique ", Actes du Congrès International de Dialectologie organisé par l'Académie de la langue basque (ed. G. Aurrekoetxea et X. Videgain), IKER 7, 179-196.

1993 : "Graphie et langue en Béarn et au Pays Basque aux XVI et XVII siècles (ancien titre: l'adstrat gasconen Pays Basque) ", Actes du colloque de Nanterre "Langues, dialectes et écriture », IEO/IPIE, 231-239. 
1995 : «Les Pyrénées, barrière ou lien linguistique ? Actes du Colloque d'historiens "Pays pyrénéens et pouvoirs centraux ( $\mathrm{XIV- \textrm {XX } ^ { e }}$ siècles) (Foix/Association des Amis des Archives de l'Ariège), I, 313-318, +8 cartes.

1996 : "Dialectologie et fonctionnalisme », La Linguistique, 31, fasc. 2, 15-31.

1996 : « Euskalerriko Atlas Etnolinguistikoaz (« De l’Atlas ethnolinguistique du

Pays Basque) ", Actes du symposium de dialectologie basque de SaintSébastien (sept. 1991), 45-50 + 22 cartes.

1997 : «Français et basque ", in Linguistique de contact, manuel publié dans le cadre des Handbücher zur Sprach-und Kommunikationswissenschaft (Walter de Gruyter, Berlin), 1260-1269.

1998 : « Baskish und Romanisch/Basque et roman », Lexikon der romanistischen Linguistik, 472, Max Niemeyer, Tübingen, 316-327.

1999 : Maurice Ravel, in Dictionnaire des Pyrénées, Privat.

2000 : « Oi arnoaren goxoa! ou des "nominaux" en basque », Lapurdum $V$.

Sous presse :

"Le basque et l'Atlas Linguarum Europae», in Actes du Colloque annuel de l'ALE tenu en 1991 à Florence.

\footnotetext{
N.B. Cette liste recense les travaux de Jacques Allières qui sont le plus directement liés à la langue basque. Mais dans d'autres articles consacrés à des langues voisines ou à des problèmes plus généraux, son savoir relatif au basque lui a permis de proposer des hypothèses fécondes. À titre d'exemple, on consultera un article paru en 1986 dans lequel, surpris de trouver en Haut-Aragon des sonantes géminées issues du latin, fait " scandaleux » au nord-ouest de la ligne La Spezia-Rimini, il n"hésite pas, en s'appuyant sur les travaux de Elcock, Michelena et Coromines, à soupçonner la phonétique basque d'avoir favorisé un tel archaïsme. Cf. Jacques Allières : "La conservation des sonantes géminées latines - LL- et - NN dans le parler de Bielsa (Haut-Aragon) : essai d'interprétation " in Variation linguistique dans l'espace. Actes du XVIT Congrès International de Linguistique et Philologie Romanes (Aix-en-Provence, 29 août - 3 septembre 1983), Vol. 6, 1986, 95-101.
} 